\title{
Effect of Deep Pentobarbital Anesthesia on Neurotransmitter Metabolism In Vivo: On the Correlation of Total Glucose Consumption With Glutamatergic Action
}

\author{
In-Young Choi, Hongxia Lei, and *Rolf Gruetter \\ Departments of Radiology and *Neuroscience, University of Minnesota, Center for MR Research, Minneapolis, Minnesota, U.S.A.
}

\begin{abstract}
Summary: The effect of deep barbiturate anesthesia on brain glucose transport, TCA cycle flux, and aspartate, glutamate, and glutamine metabolism was assessed in the rat brain in vivo using ${ }^{13} \mathrm{C}$ nuclear magnetic resonance spectroscopy at $9.4 \mathrm{~T}$ in conjunction with $\left[1-{ }^{13} \mathrm{C}\right]$ glucose infusions. Brain glucose concentrations were elevated, consistent with a twofold reduced cerebral metabolic rate for glucose $\left(\mathrm{CMR}_{\mathrm{glc}}\right)$ compared with light $\alpha$-chloralose anesthesia. Using a mathematical model of neurotransmitter metabolism, several metabolic reaction rates were extracted from the rate of label incorporation. Total oxidative glucose metabolism, $\mathrm{CMR}_{\mathrm{glc}(\mathrm{ox})}$, was $0.33 \pm 0.03$ $\mu \mathrm{mol} \cdot \mathrm{g}^{-1} \cdot \mathrm{min}^{-1}$. The neuronal TCA cycle rate was similar to that in the glia, $0.35 \pm 0.03 \mu \mathrm{mol} \cdot \mathrm{g}^{-1} \cdot \mathrm{min}^{-1}$ and $0.26 \pm 0.06$ $\mu \mathrm{mol} \cdot \mathrm{g}^{-1} \cdot \mathrm{min}^{-1}$, respectively, suggesting that neuronal energy metabolism was mainly affected. The rate of pyruvate
\end{abstract}

carboxylation was $0.03 \pm 0.01 \mu \mathrm{mol} \cdot \mathrm{g}^{-1} \cdot \mathrm{min}^{-1}$. The exchange rate between cytosolic glutamate and mitochondrial 2-oxoglutarate, $\mathrm{V}_{\mathrm{x}}$, was equal to the rate of neuronal pyruvate dehydrogenase flux. This indicates that $\mathrm{V}_{\mathrm{x}}$ is coupled to $\mathrm{CMR}_{\mathrm{glc}(\mathrm{ox})}$, implying that the malate-aspartate shuttle is the major mechanism that facilitates label exchange across the inner mitochondrial membrane. The apparent rate of glutamatergic neurotransmission, $\mathrm{V}_{\mathrm{NT}}$, was $0.04 \pm 0.01 \mu \mathrm{mol} \cdot \mathrm{g}^{-1} \cdot \mathrm{min}^{-1}$, consistent with strong reductions in electrical activity. However, the rates of cerebral oxidative glucose metabolism and glutamatergic neurotransmission, $\mathrm{CMR}_{\mathrm{glc}(\mathrm{ox})} / \mathrm{V}_{\mathrm{NT}}$, did not correlate with a 1:1 stoichiometry. Key Words: NMR - Glutamate neurotransmission-Pentobarbital-Energy metabolism-Glucose transport.
Glucose is the major fuel required to maintain normal brain function. At rest, the brain accounts for a major fraction of the body's oxidative glucose consumption even though the brain accounts only for a fraction of body mass. The brain thus has a high glucose metabolic activity, which is known to be modulated by brain function (Magistretti, 1999). In addition, a number of anesthetics can affect the rate of cerebral glucose metabolism. Of these, barbiturates can have a profound effect on brain function; they are known to depress cerebral glucose utilization and electrical activity (Hodes et al., 1985;

Received April 15, 2002; final version received July 10, 2002; accepted July 10, 2002.

Supported by National Institutes of Health grants R01NS38672 (R.G.), R21DK58004 (R.G.), the Whitaker Foundation (R.G.), and the Juvenile Diabetes Research Foundation International (R.G.). The 9.4-T instrument was funded in part by a gift from the W.M. Keck Foundation, and the Center for MR Research is supported in part by a center grant from the BTRP program of NCRR (P41RR08079).

Dr. In-Young Choi is now with the Nathan Kline Institute, Orangeburg, NY, U.S.A.

Address correspondence and reprint requests to Dr. Rolf Gruetter, Center for Magnetic Resonance Research, 2021 6th Street S.E., Minneapolis, MN 55455, U.S.A.; e-mail: gruetter@cmrr.umn.edu
Nilsson and Siesjo, 1975; Sokoloff et al., 1977; Strang and Bachelard, 1973).

Barbiturates are known to depress metabolism by inhibiting the oxidation of NADH in the respiratory chain (Aldridge and Parker, 1960; Chance and Hollunger, 1963). In cell cultures, barbiturates have been shown to reduce neuronal glutamate release and to inhibit astrocytic glutamate uptake (Qu et al., 1999; Swanson and Seid, 1998). Most studies suggest that barbiturates have an effect on both glial and neuronal cells, although depression of oxygen uptake and $\mathrm{CO}_{2}$ production from glucose has been more profound in neuronal cell cultures than in astrocyte cell cultures (Hertz et al., 1986; Yu et al., 1983).

Barbiturates can induce a near complete depression of the electrical activity in the brain (Contreras et al., 1999; Yamazaki et al., 1994) and glutamatergic neurotransmission can be greatly reduced under such conditions. Glutamatergic action occurs by neuronal release of glutamate into the synaptic cleft, interaction with postsynaptic receptors, and elimination of glutamate from the synaptic cleft by uptake into neighboring cells, and uptake into astrocytes is the dominant if not exclusive process 
(Bergles and Jahr, 1998; Danbolt, 2001). To maintain the nerve terminal glutamate concentration, the glutamate taken up by the astrocytes is converted to glutamine, which is electrophysiologically inactive, and then transported to the neuron and converted back to glutamate to be packaged into vesicles ready for renewed release. Hence, the cycling of carbon between the large neuronal pool of glutamate and the large glial pool of glutamine can be indicative of the rate of glutamatergic action.

Using ${ }^{13} \mathrm{C}$ nuclear magnetic resonance (NMR) spectroscopy, label incorporation into glutamate and glutamine can be measured in vivo (Gruetter et al., 1994; Sonnewald et al., 1997) and cerebral compartmentation can be assessed noninvasively (Gruetter et al., 1994, 2001; Shen et al., 1999; Sibson et al., 1998). We sought to assess the rates of cerebral metabolism in deep pentobarbital anesthesia in the intact rat brain in vivo. Under conditions of greatly depressed electrophysiologic activity, we expect the label transfer from glutamine to glutamate to be nearly completely suppressed. Previously, the condition of deep pentobarbital anesthesia was studied in vivo using ${ }^{13} \mathrm{C}$ NMR spectroscopy by measuring label incorporation into the glutamate $\mathrm{C} 4$ and glutamine $\mathrm{C} 4$ positions only, and it was assumed that isoelectricity results in zero transfer of glutamate from neurons to glia (Sibson et al., 1998). The measurement of more label incorporation curves reduces the number of constraints and assumptions made in the modeling (Gruetter et al., 2001). To interpret labeling of glutamate and glutamine, the compartmentation of cerebral energy metabolism into at least a neuronal and a glial compartment is needed, and the metabolism in these two compartments needs to be distinguished from glutamatergic action.

In the present study, we have extended our previous methodology and modeling to the deeply anesthetized rat brain to assess the rate of several key fluxes simultaneously. In addition, we have combined this measurement for the first time with the direct measurement of cerebral glucose concentrations, which permits insight into the degree of depression on net glucose uptake into the brain. According to the finding by Sibson et al. (1998), oxidative glucose metabolism was close to zero at isoelectricity in the brain, and thus the concentration of brain glucose (on a per milliliter brain water basis) is expected to be close to that in plasma, given the nature of the glucose transport process by facilitated diffusion (Gjedde, 1992). Finally, we assessed the exchange rate between the mitochondrial TCA cycle intermediate 2-oxoglutarate and the cytosolic amino acid glutamate, $\mathrm{V}_{\mathrm{x}}$, under conditions of extremely depressed cerebral metabolism. We previously reported that $\mathrm{V}_{\mathrm{x}}$ is on the order of the flux through pyruvate dehydrogenase, $\mathrm{V}_{\mathrm{PDH}}$ (Gruetter et al., 2001). Since oxidative glucose consumption in the brain is largely through pyruvate dehydrogenase, the reducing equivalents produced in glycolysis must be oxidized. Under normoxic conditions, the reducing equivalents are transported into the mitochondrion by several shuttles. Of these shuttles, the malate-aspartate shuttle is believed to be the most active in the brain. The exchange of carbon between mitochondrial 2-oxoglutarate and cytosolic glutamate occurs as an integral part of the malate-aspartate shuttle. Provided that the malateaspartate shuttle is a major contributor to $\mathrm{V}_{\mathrm{x}}$, this exchange rate can depend on the rate of oxidative glucose consumption, $\mathrm{CMR}_{\mathrm{glc}(\mathrm{ox})}$, and thus affect the calculated metabolic rates, that is, $\mathrm{V}_{\mathrm{PDH}}$, from glutamate turnover curves. All previous modeling of cerebral energy metabolism in the living rat brain, however, was done under the assumption that this exchange rate, $\mathrm{V}_{\mathrm{x}}$, is very fast compared with $\mathrm{V}_{\mathrm{PDH}}$ and that the net transport of reducing equivalents by the malate-aspartate shuttle is only a minor contributor to $\mathrm{V}_{\mathrm{x}}$. This assumption was made based on modeling of data from a single study, which was conducted in the awake, paralyzed rat (Mason et al., 1992). Based on our previous findings in the human brain (Gruetter et al., 2001), we expected $\mathrm{V}_{\mathrm{x}}$ to vary in conjunction with changes in the flux through the pyruvate dehydrogenase complex in different metabolic conditions. Thus, this study is also the first to evaluate whether the exchange rate, $V_{x}$, indeed varies under conditions of greatly depressed cerebral metabolism.

\section{MATERIALS AND METHODS}

\section{Animal preparation}

The study was performed according to the guidelines for the care and use of laboratory animals at the University of Minnesota and was approved by the Institutional Animal Care and Use Committee (IACUC). Male Sprague-Dawley rats $(\mathrm{n}=5$, $246 \pm 21 \mathrm{~g}$, mean $\pm \mathrm{SD}$ ) were fasted overnight with access to water before studies. Animals were anesthetized using 2\% isoflurane (Marsam Pharmaceuticals, Cherry Hill, NJ, U.S.A.) in a 1:1 mixture of nitrous oxide $\left(\mathrm{N}_{2} \mathrm{O}\right)$ and oxygen $\left(\mathrm{O}_{2}\right)$ gases for surgery. The animals were then intubated and ventilated with a pressure-driven ventilator (Kent Scientific, Litchfield, CT, U.S.A.). End tidal $\mathrm{CO}_{2}$ was monitored during surgery and experiments with a capnometer (SC-300; BCI International, Waukesha, WI, U.S.A.). Catheters were inserted into both femoral arteries for blood gases and glucose analyses, and monitoring of arterial blood pressure, and also inserted into both femoral veins for intravenous infusion of pentobarbital and glucose. Arterial blood pressure and respiratory rate and pattern were continuously monitored with a multitrace recorder (AcqKnowledge, Biopak, CA, U.S.A.).

Right after surgery, anesthesia was switched to pentobarbital solution $(10 \mathrm{mg} / \mathrm{mL}$; Abbott Laboratories, North Chicago, IL, U.S.A.) administered intravenously $\left(80 \mathrm{mg} \cdot \mathrm{kg}^{-1} \cdot \mathrm{h}^{-1}\right)$ to induce an isoelectric deep anesthesia state according to a previous report (Contreras et al., 1999). The animals were secured using a home-built Delrin holder with a bite bar and two earinserts to provide a fixed position of the skull. The animal was then placed in an acrylic holder attached to an insert in the gradient coil to ensure stability of the experimental setup during experiments. Body temperature was maintained at $37.0 \pm 0.5^{\circ} \mathrm{C}$ with a warm water circulation system based on a feedback obtained 
from a rectal temperature probe (Cole Palmer, Vernon Hills, IL, U.S.A.).

Ninety-nine percent-enriched $\left[1-{ }^{13} \mathrm{C}\right] \mathrm{D}$-glucose $(20 \% \mathrm{wt} / \mathrm{vol}$ solution; Isotec Inc., Miamisburg, OH, U.S.A.) was infused into the left femoral vein according to a previously described protocol to achieve rapid ${ }^{13} \mathrm{C}$ enrichment of plasma glucose (Choi et al., 1999). In brief, the glucose infusion protocol was as follows: After an initial infusion rate of $1.30 \mathrm{~g} \cdot \mathrm{kg}$ body $\mathrm{wt}^{-1} \cdot \mathrm{min}^{-1}$ for 6 seconds and $0.26 \mathrm{~g} \cdot \mathrm{kg}$ body $\mathrm{wt}^{-1} \cdot \mathrm{min}^{-1}$ for 30 seconds, infusion rates were dropped in an exponentially decaying fashion over 16 minutes. Subsequently, the infusion rate of glucose $\left(0.024\right.$ to $0.030 \mathrm{~g} \cdot \mathrm{kg}$ body $\left.\mathrm{wt}^{-1} \cdot \mathrm{min}^{-1}\right)$ was adjusted based on continuous monitoring of the NMR signals of brain glucose and the concomitantly measured plasma glucose concentrations to achieve stable target glycemic levels. At the end of amino acid turnover study, the infusion rate of glucose was increased in a stepwise fashion to achieve new steadystate target glycemia for the measurement of glucose transport kinetics. Arterial blood was withdrawn from the femoral artery through a Teflon-tubing line (Spectrum Chromatography, Houston, TX, U.S.A.) for blood gas analysis $\left(\mathrm{PCO}_{2}, \mathrm{PO}_{2}\right)$ and glucose measurements. Blood was immediately centrifuged after sampling, and plasma glucose concentrations were measured using a hexokinase method (Sigma, St. Louis, MO, U.S.A.). The concentration of whole blood glucose was also measured using a glucose oxidase method (Roche Diagnostics, Indianapolis, IN, U.S.A.) and calibrated against the plasma glucose measurements. Physiologic parameters were adjusted and maintained within normal ranges throughout experiments.

\section{Nuclear magnetic resonance methods}

All experiments were performed on a 9.4-T, 31-cm-bore horizontal magnet (Magnex Scientific, Abingdon, U.K.), interfaced to a Varian INOVA console (Varian, Palo Alto, CA, U.S.A.). An actively shielded gradient coil (Magnex Scientific, Abingdon, U.K.) with an 11-cm inner diameter was used, which was capable of switching $300 \mathrm{mT} / \mathrm{m}$ in $500 \mu \mathrm{s}$. A quadrature ${ }^{1} \mathrm{H}$ surface RF coil (14-mm diameter) and a linear threeturn ${ }^{13} \mathrm{C}$ coil (12-mm diameter) was used as a transceiver for ${ }^{1} \mathrm{H}$ MRI and ${ }^{13} \mathrm{C}$ NMR (Adriany and Gruetter, 1997). A 99\% ${ }^{13} \mathrm{C}$-enriched formic acid sphere was located at the center of the linear coil as an external reference, and the coil was placed on the animal's head directly over the brain. The position of the brain was identified by $\mathrm{T}_{1}$-weighted images acquired using a fast low-angle shot sequence (repetition time [TR] $=10 \mathrm{~ms}$, echo time $=5 \mathrm{~ms}$ ). The volume of interest (VOI) was placed in the brain and a nominal $510-\mu \mathrm{L}$ volume was the typical size of VOI. Three-dimensional localization based on outer volume saturation was used to ensure complete elimination of signals from extracerebral tissues as demonstrated previously (Choi et al., 1999, 2000). The efficiency of localization was verified from the absence of the natural abundance lipid signal (30.5 ppm) in spectra optimized for the amino acid region (20 to 40 ppm) because the lipid signals are not detectable in the normal brain. The localized signals (64 scans) of glycogen and glucose were acquired with spectrometer offset set to $100 \mathrm{ppm}$ (TR = 1 second) and interleaved with acquisition of localized signals (64 scans) from the amino acid region with spectrometer offset set to $30.5 \mathrm{ppm}$ (TR $=1.5$ second) to minimize chemical shift displacement errors.

The ${ }^{13} \mathrm{C}$-labeled glutamate, glycogen, and glucose resonances were quantified using the external reference method as described previously (Choi et al., 1999; Gruetter et al., 1998b). In short, in vivo ${ }^{13} \mathrm{C}$ NMR signals were quantified by comparison with the measurements of solutions containing $250 \mathrm{mmol} / \mathrm{L}$ glutamate, $\sim 400 \mathrm{mmol} / \mathrm{L}$ natural abundance oyster glycogen and $0.9 \mathrm{mmol} / \mathrm{L}$ of $99 \%$-enriched $\left[1-{ }^{13} \mathrm{C}\right] \mathrm{D}$-glucose. The external reference measurements were performed under identical experimental conditions as in vivo. The corrections of coilloading effect on sensitivity were assessed by measuring the pulse duration of $180^{\circ}$ for a square pulse applied to the signals of the ${ }^{13} \mathrm{C}$ formic acid, which is placed at the center of the ${ }^{13} \mathrm{C}$ coil. The nuclear Overhauser effect (NOE) and $\mathrm{T}_{1}$ effects were corrected by measuring the saturation factors from the ${ }^{13} \mathrm{C}$ signals with a TR of 7.5 seconds without NOE generation, which is more than fivefold longer than the $\mathrm{T}_{1}$ of the metabolites (Choi et al., 2000).

Spectra were analyzed using the peak-fitting algorithm supplied by the spectrometer software. To reduce variability, peak line widths of ${ }^{13} \mathrm{C}-{ }^{13} \mathrm{C}$ doublets were set to that of the corresponding center peak, and the frequencies of the ${ }^{13} \mathrm{C}-{ }^{13} \mathrm{C}$ doublets were set relative to the main resonance in spectra based on their relative position determined in spectra summed for 1 hour at isotopic steady state. Concentrations of ${ }^{13} \mathrm{C}$ label, e.g., ${ }^{13} \mathrm{Glu}_{4}$, were calculated from the area of the fitted peaks, including the doublets. The residual was visually inspected to verify proper convergence of the peak fitting routine.

Isotopic enrichment was measured in spectra following summation of 32 spectra acquired toward the end of the study at isotopic steady-state using isotope isomer (isotopomer) analysis (Jeffrey et al., 1999). Since those glutamate molecules labeled at $\mathrm{C} 4$ that have a $\mathrm{C} 3$ labeled as well are represented by the doublet at glutamate $\mathrm{C} 4$, that is $\left[3,4-{ }^{13} \mathrm{C}_{2}\right] \mathrm{Glu}$, the isotopic enrichment of glutamate $\mathrm{C} 3$ is given by the relative amount of doubly labeled glutamate $\mathrm{C} 4$, i.e., $\operatorname{IE}\left({ }^{13} \mathrm{Glu}_{3}\right)=$ $\left[3,4-{ }^{13} \mathrm{C}_{2}\right] \mathrm{Glu} /{ }^{13} \mathrm{Glu}_{4}$. Likewise, the isotopic enrichment of glutamate $\mathrm{C} 4$ can then be calculated from the relative amount of ${ }^{13} \mathrm{C}$ incorporated into glutamate $\mathrm{C} 4$ and the isotopic enrichment of glutamate $\mathrm{C} 3$, as follows: $\operatorname{IE}\left({ }^{13} \mathrm{Glu}_{4}\right)=\operatorname{IE}\left({ }^{13} \mathrm{Glu}_{3}\right)$ ${ }^{13} \mathrm{Glu}_{4} /{ }^{13} \mathrm{Glu}_{3}$. The same pertinent equations hold true for the glutamine $\mathrm{C} 3$ and $\mathrm{C} 4$, respectively. From the quantification of the amount of ${ }^{13} \mathrm{C}$ label incorporated and the isotopic enrichment at the given position, the total pool size of glutamate and glutamine was calculated.

\section{Modeling ${ }^{13} \mathrm{C}$ label turnover curves}

We used a recently described mathematical model of compartmentalized neurotransmitter metabolism (Gruetter et al., 2001) to derive the following metabolic rates: neuronal TCA cycle flux, $\mathrm{V}_{\mathrm{PDH}}$; glial TCA cycle flux, $\mathrm{V}_{\mathrm{g}}$; glial rate of pyruvate carboxylation, $\mathrm{V}_{\mathrm{PC}}$; exchange between (mitochondrial) 2-oxoglutarate and (cytosolic) glutamate, $\mathrm{V}_{\mathrm{x}}$; label dilution, $\mathrm{V}_{\text {out }}$; and the apparent rate of glutamate neurotransmission (glutamine-glutamate cycle rate), $\mathrm{V}_{\mathrm{NT}}$. From these metabolic rates, the following rates were calculated: glial glutamine synthetase flux, $\mathrm{V}_{\text {syn }}$; total oxidative glucose consumption, $\mathrm{CMR}_{\text {glc(ox) }}$; and the rate of ATP synthesis from glucose in neurons and glia. For a graphical representation of the model, see Fig. 5 in (Gruetter et al., 1998a) and Fig. 1 in (Gruetter et al., 2001). For the modeling, the measured pool sizes in Table 1 were

TABLE 1. Quantification of cerebral amino acid pools using an isotopomer analysis to determine isotopic enrichment and quantified amount of ${ }^{13} \mathrm{C}$ label

\begin{tabular}{cccccc}
\hline & $\mathrm{Glu}_{4}$ & $\mathrm{Glu}_{3}$ & $\mathrm{Gln}_{4}$ & $\mathrm{Gln}_{3}$ & $\mathrm{Asp}_{3}$ \\
\hline $\begin{array}{c}\text { Pool size } \\
(\mu \mathrm{mol} / \mathrm{g})\end{array}$ & $9.4 \pm 0.9$ & $9.2 \pm 0.4$ & $6.0 \pm 1.2$ & $5.7 \pm 1.8$ & $1.5 \pm 0.15$ \\
\hline
\end{tabular}

Values are mean $\pm \mathrm{SD}(\mathrm{n}=5)$.

Glu, glutamate; Gln, glutamine; Asp, aspartate. 
used. Brain glucose isotopic enrichment was assumed to have a half-life of $5 \mathrm{~min}$ and the following time courses were fitted: ${ }^{13} \mathrm{Glu}_{4}(\mathrm{t}),{ }^{13} \mathrm{Gln}_{4}(\mathrm{t}),{ }^{13} \mathrm{Glu}_{3}(\mathrm{t}),{ }^{13} \mathrm{Gln}_{3}(\mathrm{t}),{ }^{13} \mathrm{Asp}_{3}(\mathrm{t})$ using graphical fitting software (SAAM II, The SAAM Institute, Seattle, WA), which provides an error analysis (SD of the fitted parameter, from which the $95 \%$ confidence interval can be calculated) as well as a covariance analysis.

\section{Modeling glucose transport kinetics}

The steady-state measurement of brain glucose transport kinetics was analyzed using the reversible model of glucose transport kinetics (Cunningham et al., 1986) using procedures and equations previously described (Choi et al., 2001; Gruetter et al., 1998b). For the fitting, we assumed the apparent Michaelis-Menten constant $\mathrm{K}_{\mathrm{t}}$ to be the same as in light $\alpha$-chloralose anesthesia, namely, $3.3 \mathrm{mmol} / \mathrm{L}$ (Choi et al., 2001) and the model parameter $\mathrm{T}_{\text {max }} / \mathrm{CMR}_{\mathrm{glc}}$ was fitted using Eq. 4 in Gruetter et al. (1998b), where $\mathrm{T}_{\max }$ represents the apparent maximal rate of glucose transport across the blood-brain barrier.

\section{RESULTS}

The simultaneous measurement of the brain glucose concentration at different plasma glucose concentrations allowed an assessment of cerebral glucose transport kinetics at steady state. During deep pentobarbital anesthesia, the brain glucose concentration was clearly higher than what we previously reported in the lightly $\alpha$-chloralose anesthetized rats (Choi et al., 2001), as shown in Fig. 1. Note that although the brain glucose concentration was substantially higher, it was still considerably lower than the plasma glucose concentration, which implies that brain glucose consumption was still substantial. The reversible Michaelis-Menten model of glucose transport was used to fit the data as in our previous studies (Choi et al., 2001; Seaquist et al., 2001; Gruetter et al., 1998b) and yielded a ratio of maximal transport

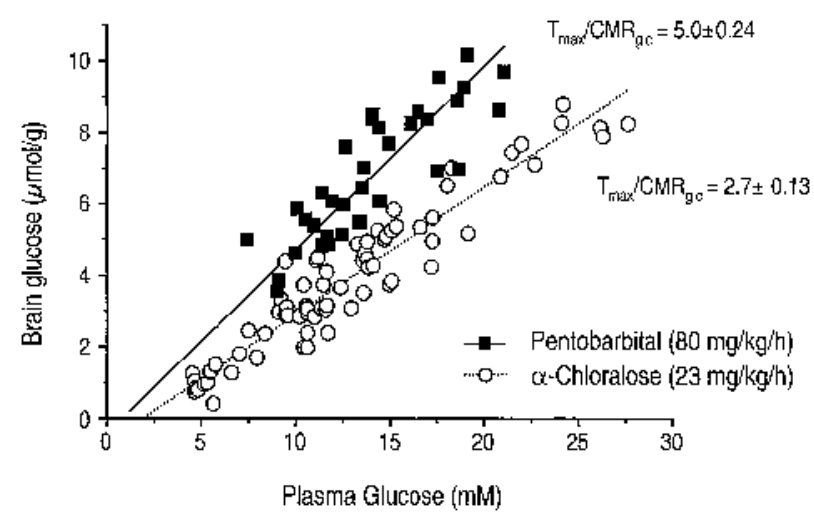

FIG. 1. Quantification of brain glucose concentration as a function of plasma glucose in rats anesthetized with pentobarbital (घ). The solid line is the best fit of the reversible MichaelisMenten model of glucose transport using Eq. 3 in Choi et al. (2001) to the data, assuming a fixed $\mathrm{K}_{\mathrm{t}}$ of $3.3 \mathrm{mmol} / \mathrm{L}$ as previously reported. For comparison, the measurement of brain glucose in the lightly $\alpha$-chloralose anesthetized rat $(\bigcirc ; 24$ $\mathrm{mg} \cdot \mathrm{kg}^{-1} \cdot \mathrm{h}^{-1}$ ) is reproduced from Choi et al. (2001), and the dotted line indicates the best fit of the glucose transport model. $\mathrm{CMR}_{\mathrm{glc}}$, cerebral metabolic rate of glucose. rate to cerebral glucose consumption rate, $\mathrm{T}_{\max } / \mathrm{CMR}_{\mathrm{glc}}$ of $5.0 \pm 0.24$. This ratio was approximately twofold higher than that in the $\alpha$-chloralose anesthetized rats (Choi et al., 2001). In these calculations, we assumed that $\mathrm{K}_{\mathrm{t}}(3.3 . \mathrm{mmol} / \mathrm{L})$ was constant between $\alpha$-chloralose and pentobarbital anesthetized rats. Even when assuming that $\mathrm{K}_{\mathrm{t}}$ varied by up to fivefold, however, the calculated $\mathrm{T}_{\text {max }} / \mathrm{CMR}_{\text {glc }}$ did not vary by more than $\pm 10 \%$. This result indicates that net glucose uptake by the brain was only reduced by $50 \%$.

Simultaneous measurement of brain glycogen concentrations indicated that brain glycogen $\mathrm{C} 1$ reached concentrations of $8.2 \pm 2.7 \mu \mathrm{mol} / \mathrm{g}$ (mean $\pm \mathrm{SD}, \mathrm{n}=3$ ) after 7 hours of $\left[1-{ }^{13} \mathrm{C}\right]$ glucose infusion. A time course of the brain glycogen $\mathrm{C} 1$ signal and concomitant quantification of ${ }^{13} \mathrm{C}$ label are shown in Fig. 2. The measurement of brain glucose and glycogen signals alternated in an interleaved fashion with measurements optimized for the spectral region containing signals from neurotransmitters and amino acids such as glutamate, glutamine, $\gamma$-aminobutyric acid, and aspartate. The turnover curves of glutamate, glutamine, and aspartate were used to extract a number of metabolic fluxes based on a recently described mathematical model of compartmentalized neurotransmitter metabolism (Gruetter et al., 2001).

Label incorporation into the glutamate $\mathrm{C} 4,{ }^{13} \mathrm{Glu}_{4}$, glutamate $\mathrm{C} 3,{ }^{13} \mathrm{Glu}_{3}$, glutamine $\mathrm{C} 4,{ }^{13} \mathrm{Gln}_{4}$, glutamine $\mathrm{C} 3,{ }^{13} \mathrm{Gln}_{3}$, and aspartate $\mathrm{C} 3$ resonances, ${ }^{13} \mathrm{Asp}_{3}$, was readily observed (Fig. 3). During pentobarbital anesthesia, optimized infusion of $99 \%$-enriched $\left[1-{ }^{13} \mathrm{C}\right]$ glucose resulted in a rapid initial rise in plasma glucose and a concomitant stable brain glucose $\mathrm{C} 1$ signal (Fig. 4A). Isotopic steady state in the amino acid pools was achieved after several hours, consistent with depressed metabolism (Fig. 3). The spectra demonstrated the resolved detection of ${ }^{13} \mathrm{C}-{ }^{13} \mathrm{C}$ isotopomers as in previous studies (Choi et al., 2000; Gruetter et al., 1994, 2001). The isotopic enrichment of glutamate $\mathrm{C} 3$ was calculated from the isotopomers within glutamate as described in Materials and Methods and similarly for glutamine: at $348 \pm 21$ min into the infusion, the isotopic enrichment of ${ }^{13} \mathrm{Glu}_{3}$ was $\operatorname{IE}\left({ }^{13} \mathrm{Glu}_{3}\right)=0.29 \pm 0.03$ and of ${ }^{13} \mathrm{Gln}_{3}$, $\operatorname{IE}\left({ }^{13} \mathrm{Gln}_{3}\right)=0.20 \pm 0.04$ (mean $\pm \mathrm{SD}, \mathrm{n}=5$ ). The isotopic enrichment of ${ }^{13} \mathrm{Glu}_{4}$ was $\operatorname{IE}\left({ }^{13} \mathrm{Glu}_{4}\right)=0.31 \pm$ 0.03 and $\operatorname{IE}\left({ }^{13} \mathrm{Gln}_{4}\right)=0.21 \pm 0.05$. The similarity of the isotopic enrichment of $\mathrm{C} 3$ and of $\mathrm{C} 4$ in both glutamate and glutamine indicates that both glutamate and glutamine were completely turned over at this late time point. From the quantified amount of ${ }^{13} \mathrm{C}$ label in $\mathrm{C} 3$ and $\mathrm{C} 4$, the total pool size of glutamate, glutamine, and aspartate was calculated assuming the same isotopic enrichment of aspartate and glutamate (Table 1). The measured time courses of label incorporation (Fig. 4C) using a mathematical model of compartmentalized neurotransmitter 
FIG. 2. (A) Observation of label incorporation into glycogen $\mathrm{C} 1\left({ }^{13} \mathrm{Glyc}_{1}\right)$ during intravenous infusion of $\left[1{ }^{13} \mathrm{C}\right]$ glucose. The ${ }^{13} \mathrm{C}$ nuclear magnetic resonance spectra shown in the stack plot correspond to 25-minute temporal resolution. Time scale from the start of $\left[1-{ }^{13} \mathrm{C}\right]$ glucose infusion is shown on the left side. Gaussian resolution enhancement $(20 \mathrm{~Hz})$ was applied before zero-filling and fast Fourier transformation. No baseline correction was applied. (B) Corresponding time course of ${ }^{13} \mathrm{C}$-labeled brain glycogen concentration.

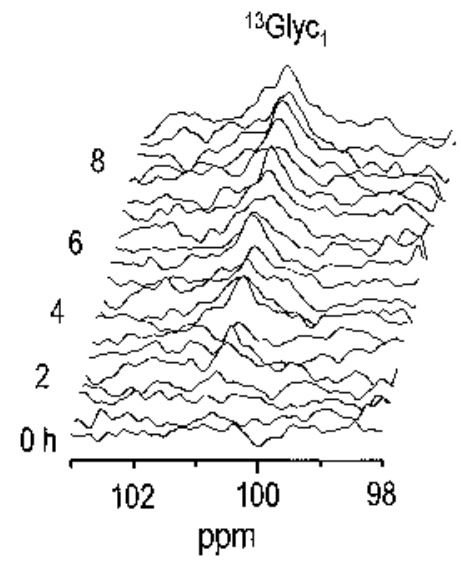

(A)

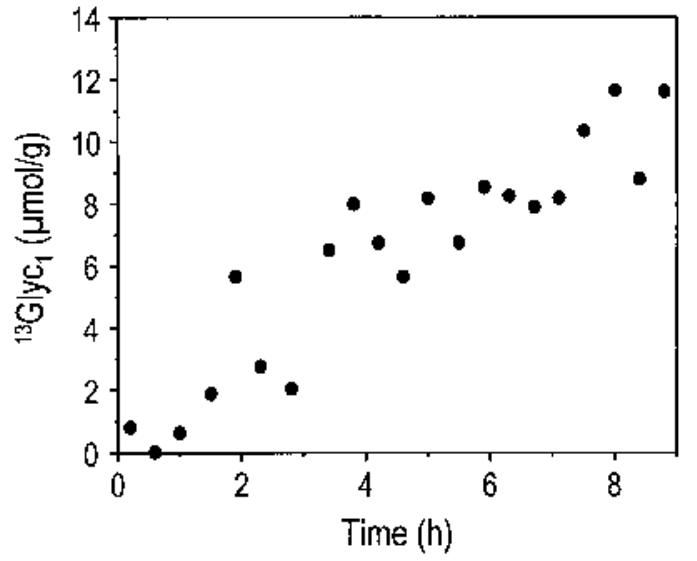

(B) metabolism (Gruetter et al., 2001) yielded several metabolic rates (Table 2).

Clearly, the rate of label incorporation into ${ }^{13} \mathrm{Glu}_{4}$ was paralleled by a label increase in ${ }^{13} \mathrm{Glu}_{3}$ and ${ }^{13} \mathrm{Gln}_{4}$, the latter indicating active metabolism in glia (Fig. 4C). Although the labeling of ${ }^{13} \mathrm{Glu}_{3}$ relative to ${ }^{13} \mathrm{Glu}_{4}$ was slower, there was no discernible lag as would be expected if the glutamate pool were turned over completely before the label continues to the next turn of the TCA cycle (Fig. 4B). To further demonstrate that our data are

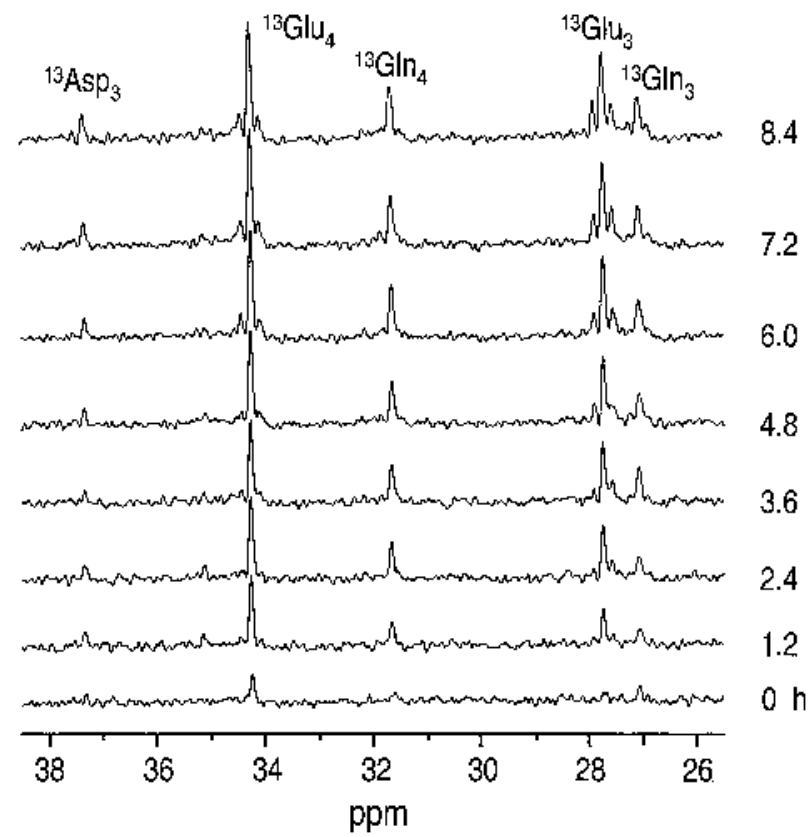

FIG. 3. Observation of label incorporation into multiple positions of glutamate (Glu), glutamine (GIn), and aspartate (Asp). Time scale from the start of $\left[1^{13} \mathrm{C}\right]$ glucose infusion is shown on the right side. Each ${ }^{13} \mathrm{C}$ magnetic resonance imaging spectrum in vivo in the stack plot is shown with 25-minute temporal resolution, 8-Hz Gaussian resolution enhancement applied before zerofilling and fast Fourier transformation. No baseline correction was applied. incompatible with a fast $\mathrm{V}_{\mathrm{x}}$ (Mason et al., 1992) and that $\mathrm{V}_{\mathrm{x}}$ was rather on the order of the rate of the TCA cycle, $\mathrm{V}_{\text {PDH }}$, we fitted $\mathrm{V}_{\mathrm{PDH}}$ and $\mathrm{V}_{\text {out }}$ to the ${ }^{13} \mathrm{Glu}_{4}(\mathrm{t})$ and ${ }^{13} \mathrm{Gln}_{4}(\mathrm{t})$ data, assuming $\mathrm{V}_{\mathrm{x}}$ was $57 \mu \mathrm{mol} \cdot \mathrm{g}^{-1} \cdot \mathrm{min}^{-1}$, as was done in previous studies (Sibson et al., 1998), while keeping the other fluxes at the values shown in row 1 of Table 2 (dashed line in Fig. 4B). The resulting $\mathrm{V}_{\mathrm{PDH}}$ was $0.14 \pm 0.02 \mu \mathrm{mol} \cdot \mathrm{g}^{-1} \cdot \mathrm{min}^{-1}$. However, the calculated ${ }^{13} \mathrm{C}$ label in glutamate $\mathrm{C} 3$ relative to that in $\mathrm{C} 4$, ${ }^{13} \mathrm{Glu}_{3} /{ }^{13} \mathrm{Glu}_{4}$ is clearly less consistent with the experimentally measured ${ }^{13} \mathrm{Glu}_{3}{ }^{13} \mathrm{Glu}_{4}$ compared to the modeling done in this study as indicated by the solid line in Fig. 4B. It is noteworthy that the observation $V_{x} \sim V_{\text {PDH }}$ did not depend on the assumed intercellular distribution of glutamate (Table 3).

The exchange rate between 2-oxoglutarate and glutamate, $\mathrm{V}_{\mathrm{x}}$, was very slow and constrained by the lower boundary afforded by the model, $\mathrm{V}_{\mathrm{PDH}}$. Removing this constraint resulted in $\mathrm{V}_{\mathrm{x}}<\mathrm{V}_{\mathrm{PDH}}$ (second row in Table 2) and resulted in an increase of $\mathrm{CMR}_{\mathrm{glc}(\mathrm{ox})}$ because of the covariance of $\mathrm{V}_{\mathrm{x}}$ and $\mathrm{V}_{\mathrm{PDH}}$. In either case, the apparent rate of glutamatergic neurotransmission, $\mathrm{V}_{\mathrm{NT}}$, was consistently close to zero (Table 2), consistent with reports suggesting isoelectricity for this dose of pentobarbital anesthesia (Contreras et al., 1999). However, the glial TCA cycle flux, $\mathrm{V}_{\mathrm{g}}$, and the rate of anaplerosis, i.e., flux through pyruvate carboxylase, $\mathrm{V}_{\mathrm{PC}}$, were substantial. In both cases presented in Table 2 , the modeling results in approximately half of the total ATP production or energy consumption being in the neuronal compartment.

\section{DISCUSSION}

This study is the first localized ${ }^{13} \mathrm{C}$ NMR study to assess total glucose consumption changes and to measure the apparent rate of glutamatergic action under deep pentobarbital anesthesia. It is also the first simultaneous measurement and modeling of cerebral glucose content, 

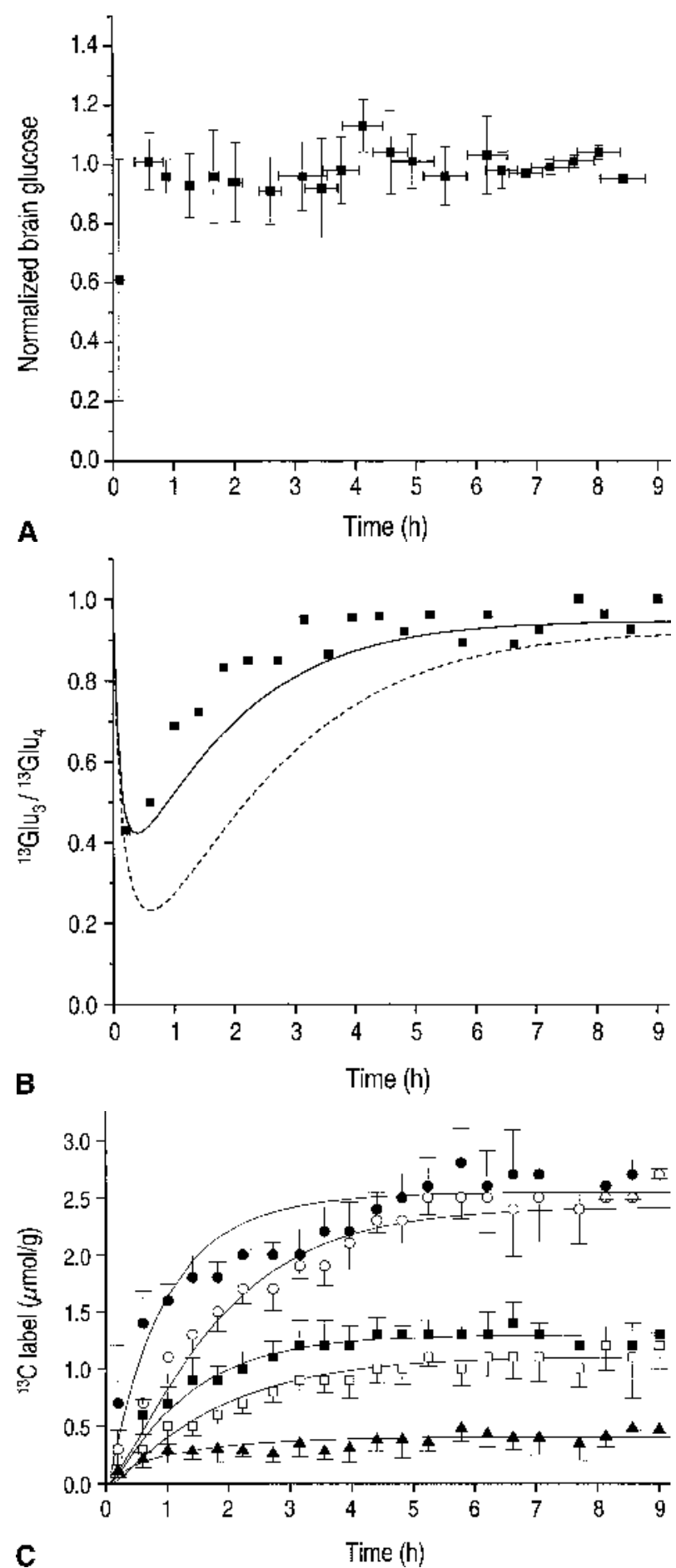

FIG. 4. (A) Time course of ${ }^{13} \mathrm{C}$-labeled brain glucose during intravenous infusion of $\left[1^{13} \mathrm{C}\right]$ glucose. (B) Comparison of label incorporation into glutamate (Glu) C4 and C3. The solid line indicates calculation using the parameters shown in row 1 of Table 2. The dashed line was calculated after fitting to the ${ }^{13} \mathrm{Glu}_{4}(\mathrm{t})$ and ${ }^{13} \mathrm{Gln}_{4}(\mathrm{t})$ data only, which resulted in $\mathrm{V}_{\mathrm{PDH}}=0.15$ $\mu \mathrm{mol} \cdot \mathrm{g}^{-1} \cdot \min ^{-1}$ when assuming $V_{\mathrm{x}}=57 \mu \mathrm{mol} \cdot \mathrm{g}^{-1} \cdot \mathrm{min}^{-1}$ as in Sibson et al. (1998). (C) Time course of label incorporation into multiple positions of amino acids in the rat brain $\left({ }^{13} \mathrm{Glu}_{4} \quad ;{ }^{13} \mathrm{Gln}_{4}\right.$ $[\square] ;{ }^{13} \mathrm{Glu}_{3}\left[\mathrm{O} ;{ }^{13} \mathrm{Gln}_{3}[\square] ;{ }^{13} \mathrm{Asp}_{3}[\mathbf{\Delta}]\right)$. The data represent mean \pm SD of all five studies, and the solid lines represent the best fit of the model to the data. and label incorporation into multiple positions in amino acids and neurotransmitters such as glutamate, glutamine, and aspartate. The increased information content achieved in this study allowed a robust assessment of cerebral metabolic rates in the glial and the neuronal compartments.

For example, the exchange between mitochondrial 2-oxoglutarate and cytosolic glutamate, $\mathrm{V}_{\mathrm{x}}$, involves transport of charged acids across the heavily polarized inner mitochondrial membrane and is achievable only through transporters (LaNoue and Tischler, 1974). $V_{x}$ being on the order of the neuronal TCA cycle rate, $\mathrm{V}_{\mathrm{PDH}}$ (Table 2) implies that the malate-aspartate shuttle is the major mechanism in the deeply anesthetized rat brain, assuming that the glycerol-phosphate shuttle is a minor contributor to the flux of reducing equivalents from the cytosol into the mitochondria. Together these results also show that this exchange can depend on the metabolic activity of the cell. This is in agreement with measurements in the perfused heart, where the exchange rate was found to be on the order of the TCA cycle rate (Yu et al., 1997). Studies have suggested that the other major shuttle that transports reducing equivalents from the cytosol to the mitochondrion, namely, the glycerolphosphate shuttle, may be active in the heart (Chatham et al., 1995) and the liver (Poso, 1979). When assuming that the glycerol-phosphate shuttle is also active in the brain, the condition that $\mathrm{V}_{\mathrm{x}}$ is larger than $\mathrm{V}_{\mathrm{PDH}}$ can be eliminated from the fitting. In this case, $\mathrm{V}_{\mathrm{x}}$ was indeed lower than $\mathrm{V}_{\mathrm{PDH}}$ (Table 2), suggesting that fluxes through shuttles other than the malate-aspartate shuttle may not be negligible in the brain in vivo. It was reported, however, that the degree of inhibition of transaminase flux and, therefore, malate-aspartate shuttle activity, was proportional to the degree of reduced oxygen consumption in the brain (Fitzpatrick et al., 1983), suggesting that very few reducing equivalents can be transported by other shuttle mechanisms. Removing the constraint $V_{x} \geq V_{P D H}$ has a strong effect on some of the rates. Because of the known negative covariance of $\mathrm{V}_{\mathrm{PDH}}$ and $\mathrm{V}_{\mathrm{x}}$, the increase in $\mathrm{V}_{\mathrm{PDH}}$ was not an unexpected result.

The rate of label incorporation into glutamate, glutamine, and aspartate was analyzed using a mathematical model of compartmentalized neurotransmitter metabolism. The derived metabolic rates provide further insight into the action of pentobarbital and depressed electrical activity on cerebral metabolism in neurons and glia. The apparent rate of neurotransmission, $\mathrm{V}_{\mathrm{NT}}$, was reduced to very close to zero, $0.04 \mu \mathrm{mol} \cdot \mathrm{g}^{-1} \cdot \mathrm{min}^{-1}$, which implies suppression of glutamatergic action, consistent with almost complete isoelectricity. It is interesting to note that under the present conditions, anaplerosis, although quantitatively small, constitutes about half of the flux through glutamine synthetase, $\mathrm{V}_{\mathrm{syn}}$. Conversely, this 
TABLE 2. Derived metabolic fluxes $\left(\mu \mathrm{mol} \cdot \mathrm{g}^{-1} \cdot \mathrm{min}^{-1}\right.$ ) by fitting the model (from Gruetter et al., 2001) to the time courses in Figure $4 C$

\begin{tabular}{|c|c|c|c|c|c|c|c|}
\hline $\mathrm{V}_{\mathrm{x}}$ constraint & $\mathrm{V}_{\mathrm{PDH}}$ & $\mathrm{V}_{\mathrm{x}}$ & $\mathrm{CMR}_{\text {glc(ox) }}$ & $\mathrm{V}_{\mathrm{NT}}$ & $\mathrm{V}_{\mathrm{PC}}$ & $\mathrm{V}_{\mathrm{g}}$ & $\mathrm{V}_{\mathrm{syn}}$ \\
\hline $\mathrm{V}_{\mathrm{x}} \geq \mathrm{V}_{\mathrm{PDH}}$ & $0.35 \pm 0.03$ & $0.35 \pm 0.03$ & $0.33 \pm 0.03$ & $0.04 \pm 0.01$ & $0.03 \pm 0.01$ & $0.26 \pm 0.06$ & $0.07 \pm 0.01$ \\
\hline none & $0.41 \pm 0.05$ & $0.22 \pm 0.05$ & $0.38 \pm 0.04$ & $0.04 \pm 0.01$ & $0.04 \pm 0.01$ & $0.28 \pm 0.07$ & $0.07 \pm 0.01$ \\
\hline
\end{tabular}

Values are given as mean $\pm \mathrm{SE}$.

$\mathrm{V}_{\mathrm{PDH}}$, the flux through pyruvate dehydrogenase; $\mathrm{V}_{\mathrm{x}}$, the exchange rate between the mitochondrial TCA cycle intermediate 2-oxoglutarate and the cytosolic amino acid glutamate; $\mathrm{CMR}_{\mathrm{glc}(\mathrm{ox})}$, the rate of oxidative glucose consumption; $\mathrm{V}_{\mathrm{NT}}$, the apparent rate of glutamatergic neurotransmission; $\mathrm{V}_{\mathrm{PC}}$, the rate of pyruvate carboxylase; $\mathrm{V}_{\mathrm{g}}$, the glial TCA cycle flux; $\mathrm{V}_{\mathrm{syn}}$, the flux through glutamine synthetase.

means that glutamatergic action is not the dominant contributor to glutamine synthesis. In this context, it was intriguing to note that the rate of labeling for glutamine $\mathrm{C} 4,{ }^{13} \mathrm{Gln}_{4}$, apparently reached steady state as fast as the glutamate $\mathrm{C} 4,{ }^{13} \mathrm{Glu}_{4}$, as judged from the label incorporation shown in Figs. 3 and $4 \mathrm{C}$. This is direct experimental evidence for either a high metabolic rate in the glial compartment relative to the neuronal compartment or a very fast rate of label transfer from neuronal glutamate to glial glutamine, $\mathrm{V}_{\mathrm{NT}}$. Faster glutamatergic action (represented by $\mathrm{V}_{\mathrm{NT}}$ ) under deep anesthetic states compared with states with higher electrical activity, however, is very unlikely and would be inconsistent with the low $\mathrm{V}_{\mathrm{NT}}$.

Our results suggest that glial energy consumption is quite considerable and amounts to approximately half of the total ATP synthesis from glucose under deep pentobarbital anesthesia. This is rather surprising when we consider that it is generally assumed that most of the oxidative glucose metabolism is in the neuronal compartment, as we have observed, for instance, in the conscious brain (Gruetter et al., 2001). Therefore, our current finding of substantial glial energy metabolism implies a major site of action for barbiturates in the neuronal compartment. In cell cultures, barbiturates have been shown to depress neuronal metabolism more than in astrocytes (Hertz et al., 1986). In addition, some studies have reported increased deoxyglucose uptake in cultured astrocytes with increasing pentobarbital anesthesia (Swanson and Seid, 1998). Barbiturates are thought to act on the respiratory chain and the overall reduced oxygen consumption (Blacklock et al., 1987; Donegan et al., 1985), and thus likely reflects the larger effect of pentobarbital on the neuronal compartment than the glial compartment (Hertz et al., 1986; Yu et al., 1983).

In our study, the simultaneous measurement of brain glucose content allowed an assessment of the effect of pentobarbital on overall glucose metabolism. The considerable gradient remaining between brain and plasma glucose concentrations, as can be seen in Fig. 1, indicates substantial glucose uptake during deep pentobarbital anesthesia. Modeling glucose transport indicates that $\mathrm{CMR}_{\text {glc }}$ was half of that in the light $\alpha$-chloralose anesthetized rat brain. In this analysis, it was assumed that the apparent Michaelis-Menten constant for glucose transport, $\mathrm{K}_{\mathrm{t}}$, and the maximal apparent glucose transport rate, $\mathrm{T}_{\max }$, were not affected by the deep pentobarbital anesthesia. A recent report suggested that the transport affinity for glucose may change under pentobarbital anesthesia in cultured cells and erythrocytes (Haspel et al., 1999). When we allow a fivefold change in the apparent Michaelis-Menten constant $\mathrm{K}_{\mathrm{t}}\left(\mathrm{K}_{\mathrm{t}}\right.$ ranging from 1 to 5 $\mathrm{mmol} / \mathrm{L}), \mathrm{T}_{\max } / \mathrm{CMR}_{\mathrm{glc}}$ was affected by approximately $20 \%$, which did not change the conclusions of this study, namely, that overall glucose metabolism was still considerable. If it is assumed that the twofold reduction in glucose metabolic rate reflects mainly changes in the neuronal energy metabolism, then we estimate that under $\alpha$-chloralose anesthesia, glial energy metabolism represents only approximately $25 \%$ of total energy metabolism as measured by labeling from glucose.

The decrease in cerebral metabolic rate under pentobarbital anesthesia is substantially less than what has been reported in an earlier study (Sibson et al., 1998),

TABLE 3. Effect of assumed intercellular distribution on derived metabolic fluxes $\left(\mu \mathrm{mol} \cdot \mathrm{g}^{-1} \cdot \mathrm{min}^{-1}\right)$ by fitting the model (from Gruetter et al., 2001) to the time courses in Figure 4C

\begin{tabular}{|c|c|c|c|c|c|c|c|}
\hline$\alpha$ & $\mathrm{V}_{\mathrm{PDH}}$ & $V_{x}$ & $\mathrm{CMR}_{\mathrm{glc}(\mathrm{ox})}$ & $\mathrm{V}_{\mathrm{NT}}$ & $\mathrm{V}_{\mathrm{PC}}$ & $\mathrm{V}_{\mathrm{g}}$ & $\mathrm{V}_{\text {syn }}$ \\
\hline 0.02 & $0.39 \pm 0.03$ & $0.39 \pm 0.03$ & $0.34 \pm 0.03$ & $0.05 \pm 0.02$ & $0.03 \pm 0.01$ & $0.23 \pm 0.06$ & $0.08 \pm 0.01$ \\
\hline 0.05 & $0.37 \pm 0.03$ & $0.37 \pm 0.03$ & $0.35 \pm 0.04$ & $0.05 \pm 0.02$ & $0.03 \pm 0.01$ & $0.27 \pm 0.07$ & $0.08 \pm 0.01$ \\
\hline 0.10 & $0.33 \pm 0.03$ & $0.33 \pm 0.03$ & $0.38 \pm 0.05$ & $0.03 \pm 0.02$ & $0.04 \pm 0.01$ & $0.35 \pm 0.09$ & $0.07 \pm 0.01$ \\
\hline 0.16 & $0.29 \pm 0.02$ & $0.29 \pm 0.02$ & $0.53 \pm 0.07$ & $0.00 \pm 0.00$ & $0.07 \pm 0.01$ & $0.63 \pm 0.13$ & $0.07 \pm 0.01$ \\
\hline 0.21 & $0.26 \pm 0.02$ & $0.26 \pm 0.02$ & $0.54 \pm 0.06$ & $0.00 \pm 0.00$ & $0.07 \pm 0.01$ & $0.68 \pm 0.12$ & $0.07 \pm 0.01$ \\
\hline
\end{tabular}

Values are given as mean \pm SE. $\alpha$ represents the fraction of total glutamate that was assumed to be in the glial compartment $(\alpha=0.05$ was used in Table 2).

$\mathrm{V}_{\mathrm{PDH}}$, the flux through pyruvate dehydrogenase; $\mathrm{V}_{\mathrm{x}}$, the exchange rate between the mitochondrial TCA cycle intermediate 2-oxoglutarate and the cytosolic amino acid glutamate; $\mathrm{CMR}_{\text {glc(ox)}}$, the rate of oxidative glucose consumption; $\mathrm{V}_{\mathrm{NT}}$, the apparent rate of glutamatergic neurotransmission; $\mathrm{V}_{\mathrm{PC}}$, the rate of pyruvate carboxylase; $\mathrm{V}_{\mathrm{g}}$, the glial TCA cycle flux; $\mathrm{V}_{\mathrm{syn}}$, the flux through glutamine synthetase. 
where brain glucose transport under these conditions was not assessed. That study stated that cerebral metabolism in coma (a pentobarbital dose of 40 to $60 \mathrm{mg} \cdot \mathrm{kg}^{-1} \cdot \mathrm{h}^{-1}$ intraperitoneally) was depressed to $10 \%$ of the basal metabolism. The study further reported that most of the cerebral oxidative glucose consumption rate was coupled in a 1:1 stoichiometric fashion to glutamatergic action. According to previous measurements of brain glucose content as a function of plasma glucose content in the awake rat (Mason et al., 1992) and the proposed 10-fold reduction in metabolism in coma (Sibson et al., 1998), brain glucose concentrations should rise to values close to the plasma glucose concentration according to the nature of the glucose transport process by facilitated diffusion. Our analysis of the glucose transport kinetics, however, is consistent with only a twofold reduction in the metabolic rate.

These findings shed light on the interpretation of "stoichiometric coupling of brain glucose metabolism and glutamatergic neuronal activity" (Sibson et al., 1998), which was recently challenged based on data obtained in the conscious human brain where glial and neuronal metabolism was simultaneously assessed (Gruetter et al., 2001). In the study by Sibson et al. and more recent reviews of that paper (Shulman and Rothman, 2001), it was suggested that the total oxidative glucose consumption in the brain is linearly correlated with glutamatergic action with a 1:1 stoichiometry. Energy metabolism in the glial compartment under deep pentobarbital anesthesia, however, was not assessed in that study, and neither was the glutamate-glutamine cycle (represented by $\mathrm{V}_{\mathrm{NT}}$ in our modeling); instead it was assumed to be zero at isoelectricity. Last, a further limitation of that study was that the turnover of only ${ }^{13} \mathrm{Glu}_{4}(\mathrm{t})$ and ${ }^{13} \mathrm{Gln}_{4}(\mathrm{t})$ was measured, which did not permit the measurement of $\mathrm{V}_{\mathrm{x}}$. Instead, that study was based on an assumed $\mathrm{V}_{\mathrm{x}}$ of approximately $50 \mu \mathrm{mol} \cdot \mathrm{g}^{-1} \cdot \mathrm{min}^{-1}$ (Mason et al., 1992). However, it is not clear to what extent the previous study by Mason et al. represents normal physiology, since data obtained from paralyzed, awake rats following tracheotomy and scalp retraction were used. In contrast, the present study reports a $\mathrm{V}_{\mathrm{x}}$ of $0.35 \mu \mathrm{mol} \cdot \mathrm{g}^{-1} \cdot \mathrm{min}^{-1}$, our previous study in awake humans reported 0.58 $\mu \mathrm{mol} \cdot \mathrm{g}^{-1} \cdot \mathrm{min}^{-1}$, and a recent study in $\alpha$-chloralose anesthetized rats reported $0.9 \mu \mathrm{mol} \cdot \mathrm{g}^{-1} \cdot \mathrm{min}^{-1}$ (Henry et al., 2002). In all studies of normal, anesthetized rats or humans, $\mathrm{V}_{\mathrm{x}}$ was on the order of $\mathrm{V}_{\mathrm{PDH}}$, which is strong supporting evidence that the malate-aspartate shuttle can be measured by ${ }^{13} \mathrm{C}$ NMR in the brain and that it is a major flux-controlling mechanism.

Our studies suggest that the energy required for glutamate signaling is very low. In the present study, the total ATP consumption is estimated at 10 $\mu \mathrm{mol} \cdot \mathrm{g}^{-1} \cdot \min ^{-1}$, of which approximately $\mathrm{V}_{\mathrm{NT}} \times 2.25=$ $0.1 \mu \mathrm{mol} \cdot \mathrm{g}^{-1} \cdot \mathrm{min}^{-1}$ is devoted to the restoration of the ion concentration following glutamate uptake into astrocytes and conversion of the glutamate to glutamine and then export back to neurons. This amounts to glutamate signaling requiring less than $2 \%$ of the glial (or neuronal) energy consumed under deep anesthesia, where electrical activity is greatly or even completely depressed. A calculation of the ATP synthesis required for glutamate cycling from our previous study (Gruetter et al., 2001) indicated that approximately $3 \%$ of total ATP is devoted to that task in the conscious human brain. These calculations are in excellent agreement with recent theoretical considerations (Attwell and Laughlin, 2001).

Because the present results with the more complete modeling and more extensive analysis of cerebral energy metabolism suggest that there is considerable oxidative ATP synthesis in glia and that cerebral glucose consumption is still substantial under deep pentobarbital anesthesia, the "molar stoichiometric coupling of total glucose consumption with neuronal glutamate release" (Sibson et al., 1998) hardly exists. It was also suggested in our previous study (Gruetter et al., 2001) that there is potentially a correlation between neuronal glutamate release, $\mathrm{V}_{\mathrm{NT}}$, and the TCA cycle rate in neurons, $\mathrm{V}_{\mathrm{PDH}}$. However, a correlation between $\mathrm{V}_{\mathrm{NT}}$, reflecting the glial energy demands of glutamate recycling, and $\mathrm{V}_{\mathrm{PDH}}$, representing neuronal energy metabolism, eliminates the chemical basis for the proposed molar stoichiometry between glucose metabolism and glutamatergic action. Therefore, in light of these results, the findings by Sibson et al. require reinterpretation and additional work is needed. Based on the present results in the deeply anesthetized rat brain and our recent results in the conscious human brain (Gruetter et al., 2001), we offer the following interpretation: there is undoubtedly a coupling between glutamatergic action and glial energy metabolism, as suggested by the increased deoxyglucose uptake with increasing extracellular glutamate concentration (Magistretti et al., 1993) and increased oxygen consumption (Eriksson et al., 1995). The precise relation between changes in neurotransmission rates and energy metabolism, however, has not yet been satisfactorily established.

\section{REFERENCES}

Adriany G, Gruetter R (1997) A half volume coil for efficient proton decoupling in humans at 4 Tesla. J Magn Reson 125:178-184

Aldridge WN, Parker VH (1960) Barbiturates and oxidative phosphorylation. Biochem J 76:47-56

Attwell D, Laughlin SB (2001) An energy budget for signaling in the grey matter of the brain. J Cereb Blood Flow Metab 21:1133-1145

Bergles DE, Jahr CE (1998) Glial contribution to glutamate uptake at Schaffer collateral-commissural synapses in the hippocampus. $J$ Neurosci 18:7709-7716

Blacklock JB, Oldfield EH, Di Chiro G, Tran D, Theodore W, Wright DC, Larson SM (1987) Effect of barbiturate coma on glucose utilization in normal brain versus gliomas: positron emission tomography studies. J Neurosurg 67:71-75

Chance B, Hollunger G (1963) Inhibition of electron and energy transfer in mitochondria. J Biol Chem 278:418-431 
Chatham JC, Forder JR, Glickson JD, Chance EM (1995) Calculation of absolute metabolic flux and the elucidation of the pathways of glutamate labeling in perfused rat heart by ${ }^{13} \mathrm{C}$ NMR spectroscopy and nonlinear least squares analysis. J Biol Chem 270:7999-8008

Choi I-Y, Tkac I, Ugurbil K, Gruetter R (1999) Noninvasive measurements of $\left[1-{ }^{13} \mathrm{C}\right]$ glycogen concentrations and metabolism in rat brain in vivo. $J$ Neurochem 73:1300-1308

Choi I-Y, Tkac I, Gruetter R (2000) Single-shot, three-dimensional "non-echo" localization method for in vivo NMR spectroscopy. Magn Reson Med 44:387-394

Choi I-Y, Lee S-P, Kim S-G, Gruetter R (2001) In vivo measurements of brain glucose transport using the reversible Michaelis-Menten model and simultaneous measurements of cerebral blood flow changes during hypoglycemia. J Cereb Blood Flow Metab 21:653663

Contreras MA, Chang MC, Kirkby D, Bell JM, Rapoport SI (1999) Reduced palmitate turnover in brain phospholipids of pentobarbital-anesthetized rats. Neurochem Res 24:833-841

Cunningham VJ, Hargreaves RJ, Pelling D, Moorhouse SR (1986) Regional blood-brain glucose transfer in the rat: a novel doublemembrane kinetic analysis. J Cereb Blood Flow Metab 6:305-314

Danbolt NC (2001) Glutamate uptake. Prog Neurobiol 65:1-105

Donegan JH, Traystman RJ, Koehler RC, Jones MD Jr, Rogers MC (1985) Cerebrovascular hypoxic and autoregulatory responses during reduced brain metabolism. Am J Physiol 249:H421-H429

Eriksson G, Peterson A, Iverfeldt K, Walum E (1995) Sodiumdependent glutamate uptake as an activator of oxidative metabolism in primary astrocyte cultures from newborn rat. Glia 15:152156

Fitzpatrick SM, Cooper AJ, Duffy TE (1983) Use of beta-methyleneD,L-aspartate to assess the role of aspartate aminotransferase in cerebral oxidative metabolism. J Neurochem 41:1370-1383

Gjedde A (1992) Blood-brain glucose transfer. In: Physiology and pharmacology of the blood-brain barrier (Bradbury M, ed), New York: Springer Verlag, pp 65-117

Gruetter R, Novotny EJ, Boulware SD, Mason GF, Rothman DL, Shulman GI, Prichard JW, Shulman RG (1994) Localized ${ }^{13} \mathrm{C}$ NMR spectroscopy in the human brain of amino acid labeling from D-[1${ }^{13}$ C]glucose. J Neurochem 63:1377-1385

Gruetter R, Seaquist E, Kim S-W, Ugurbil K (1998a) Localized in vivo ${ }^{13} \mathrm{C}$ NMR of glutamate metabolism: initial results at 4 Tesla. Dev Neurosci 20:380-388

Gruetter R, Ugurbil K, Seaquist ER (1998b) Steady-state cerebral glucose concentrations and transport in the human brain. J Neurochem 70:397-408

Gruetter R, Seaquist ER, Ugurbil K (2001) A mathematical model of compartmentalized neurotransmitter metabolism in the human brain. Am J Physiol Endocrinol Metab 281:E100-112

Haspel HC, Stephenson KN, Davies-Hill T, El-Barbary A, Lobo JF, Croxen RL, Mougrabi W, Koehler-Stec EM, Fenstermacher JD, Simpson IA (1999) Effects of barbiturates on facilitative glucose transporters are pharmacologically specific and isoform selective. J Membr Biol 169:45-53

Henry P-G, Lebon V, Vaufrey F, Brouillet E, Hantraye P, Bloch G (2002) Decreased TCA cycle rate in the rat brain after acute 3-NP treatment measured by in vivo ${ }^{1} \mathrm{H}-\left\{{ }^{13} \mathrm{C}\right\}$ NMR spectroscopy. $J$ Neurochem 82:857-866

Hertz E, Shargool M, Hertz L (1986) Effects of barbiturates on energy metabolism by cultured astrocytes and neurons in the presence of normal and elevated concentrations of potassium. Neuropharmacology 25:533-539

Hodes JE, Soncrant TT, Larson DM, Carlson SG, Rapoport SI (1985) Selective changes in local cerebral glucose utilization induced by phenobarbital in the rat. Anesthesiology 63:633-639

Jeffrey FM, Reshetov A, Storey CJ, Carvalho RA, Sherry AD, Malloy
CR (1999) Use of a single ${ }^{13} \mathrm{C}$ NMR resonance of glutamate for measuring oxygen consumption in tissue. Am J Physiol 277: E1111-1121

LaNoue KF, Tischler ME (1974) Electrogenic characteristics of the mitochondrial glutamate-aspartate antiporter. J Biol Chem 249:7522-7528

Magistretti PJ (1999) Brain energy metabolism. In: Fundamental neuroscience (Zigmond MJ, Bloom FE, Landis SC et al., eds), San Diego: Academic Press, pp 389-413

Magistretti PJ, Sorg O, Yu N, Martin JL, Pellerin L (1993) Neurotransmitters regulate energy metabolism in astrocytes: implications for the metabolic trafficking between neural cells. Dev Neurosci 15:306-312

Mason GF, Rothman DL, Behar KL, Shulman RG (1992) NMR determination of the TCA cycle rate and alpha-ketoglutarate/glutamate exchange rate in rat brain. $J$ Cereb Blood Flow Metab 12:434-447

Nilsson L, Siesjo BK (1975) The effect of phenobarbitone anaesthesia on blood flow and oxygen consumption in the rat brain. Acta Anesthesiol Scand Suppl 57:18-24

Poso AR (1979) Shuttles for translocation of NADH in isolated liver cells from fed rats during oxidation of xylitol. Acta Chem Scand B B33:93-99

Qu H, Faero E, Jorgensen P, Dale O, Gisvold SE, Unsgard G, Sonnewald U (1999) Decreased glutamate metabolism in cultured astrocytes in the presence of thiopental. Biochem Pharmacol 58:1075-1080

Seaquist ER, Damberg GS, Tkac I, Gruetter R (2001) The effect of insulin on in vivo cerebral glucose concentrations and rates of glucose transport/metabolism in humans. Diabetes 50:2203-2209

Shen J, Petersen KF, Behar KL, Brown P, Nixon TW, Mason GF, Petroff OA, Shulman GI, Shulman RG, Rothman DL (1999) Determination of the rate of the glutamate/glutamine cycle in the human brain by in vivo ${ }^{13} \mathrm{C}$ NMR. Proc Natl Acad Sci U S A 96:8235-8240

Shulman RG, Rothman DL (2001) ${ }^{13} \mathrm{C}$ NMR of intermediary metabolism: implications for systemic physiology. Annu Rev Physiol 63:15-48

Sibson NR, Dhankhar A, Mason GF, Rothman DL, Behar KL, Shulman RG (1998) Stoichiometric coupling of brain glucose metabolism and glutamatergic neuronal activity. Proc Natl Acad Sci U S A 95:316-321

Sokoloff L, Reivich M, Kennedy C, Des Rosiers MH, Patlak CS, Pettigrew KD, Sakurada O, Shinohara M (1977) The $\left[{ }^{14} \mathrm{C}\right]$ deoxyglucose method for the measurement of local cerebral glucose utilization: theory, procedure, and normal values in the conscious and anesthetized albino rat. J Neurochem 28:897-916

Sonnewald U, Westergaard N, Schousboe A (1997) Glutamate transport and metabolism in astrocytes. Glia 21:56-63

Strang RH, Bachelard HS (1973) Rates of cerebral glucose utilization in rats anaesthetized with phenobarbitone. J Neurochem 20:987996

Swanson RA, Seid LL (1998) Barbiturates impair astrocyte glutamate uptake. Glia 24:365-371

Yamazaki S, DeGeorge JJ, Bell JM, Rapoport SI (1994) Effects of pentobarbital on incorporation of plasma palmitate into rat brain Anesthesiology 80:151-158

Yu AC, Hertz E, Hertz L (1983) Effects of barbiturates on energy and intermediary metabolism in cultured astrocytes. Prog Neuropsychopharmacol Biol Psychiatry 7:691-696

Yu X, Alpert NM, Lewandowski ED (1997) Modeling enrichment kinetics from dynamic ${ }^{13} \mathrm{C}$ magnetic resonance imaging spectra: theoretical analysis and practical considerations. Am J Physiol 41:C2037-C2048 